\section{Impact of Demethylation Inhibitor (DMI) Fungicides on Clipping Yield and Rooting Depth of Creeping Bentgrass}

\author{
Nathaniel A. Mitkowski ${ }^{1}$ and Arielle Chaves \\ Department of Plant Sciences and Entomology, University of Rhode Island, \\ 9 East Alumni Avenue, Kingston, RI 02881
}

Additional index words. plant growth regulator, fungicide, putting green, phytotoxicity, paclobutrazol, chlorothalonil, iprodione, propiconazole, metconazole, myclobutanil, tebuconazole, triadimefon, triticonazole

\begin{abstract}
Demethylation inhibitor fungicides (DMIs) have been used to manage a wide range of turfgrass diseases for many decades. Unfortunately, this class of fungicide can have unwanted plant growth regulator (PGR) effects on amenity turfgrasses. Recently, a number of new DMI fungicides have been registered for turfgrasses and are seeing expanded use. To determine if differences exist in the PGR-related activity among products, a 2-year field study was conducted examining six different DMI fungicides. Fungicides were applied to creeping bentgrass maintained at $0.33 \mathrm{~cm}$ and applied five or six times every 14 days at equivalent active ingredient rates. The results demonstrated that although paclobutrazol statistically reduced clipping weights, there was very little effect from DMI fungicides. In the first study year, propiconazole did produce higher clipping weights on two rating dates but this was not observed in the second year. Rooting depth was unaffected by any of the chemicals in either year. Although phytotoxicity may be a concern of turfgrass managers when applying DMI fungicides during the summer, it seems unlikely that these materials applied without the additional use of labeled PGRs will have any noticeable negative effects on foliar and root growth of creeping bentgrass in New England.
\end{abstract}

Demethylation inhibitor fungicides [also known as sterol inhibitor fungicides, belonging to the Fungicide Resistance Action Committee (FRAC) Code Group \#3 (FRAC, 2012)] are widely used on turfgrasses throughout the United States. These fungicides are labeled for use on golf courses, athletic fields, sod farms, commercial properties, and on home lawns. The success of this group of materials stems from its relatively broad spectrum of activity and relatively low mammalian toxicity (Kamrin, 1997). In addition, this group of fungicides is relatively old and has been in use in turf for at least four decades (Kane and Smiley, 1983). Active ingredients belonging to this class move acropetally and all those registered for use in turf management belong to the triazole subgroup with the exception of fenarimol, which is a pyrimidine (FRAC, 2012). In addition, resistance development to this class of fungicide is generally slow, occurring quantitatively, and this group is considered to be a low to moderate risk for resistance development (FRAC, 2012). Active ingredients that are currently registered for use in the United States include: fenarimol, myclobutanil, metconazole, propiconazole, tebuconazole, triadimefon, and triticonazole

Received for publication 10 May 2013. Accepted for publication 17 June 2013.

${ }^{1}$ To whom reprint requests should be addressed; e-mailmitkowski@uri.edu. (fenarimol use is voluntarily cancelled on 31 July 2013 but end users will be allowed to continue previously labeled applications until supplies are exhausted).

Unfortunately, DMI fungicides have long been known to cause unintentional PGR effects when applied to foliage or applied as a soil drench that is ultimately translocated upward to plant crowns and leaves. On turfgrasses and other plants, the most noticeable effect of DMI fungicide use is often a darkening of foliar color (Buchenauer and Grossman, 1977; Kane and Smiley, 1983; Reicher and Throssell, 1997). Additional effects include delayed senescence and a general reduction in growth, often accompanied by a reduction in turfgrass quality. Some formulations of these fungicides can also cause phytotoxicity to turfgrasses when applied in high heat, at rates above label, on warm-season grasses, or on annual bluegrass (Poа аппиа L.) greens; DMI fungicides also affect the gibberellic acid synthesis pathway in plants (Bigelow et al., 1995; Buchenauer and Grossman, 1977; Kane and Smiley, 1983; McCullough et al., 2006; Pennypacker et al., 1982; Reicher and Throssell, 1997). The DMI-related products developed and used specifically as PGRs (i.e., gibberellic acid inhibitors) have conversely shown low levels of fungicidal affects in turfgrasses (Burpee et al., 1996). Because of the potential negative impacts of DMI fungicides, end users often rotate in other fungicide classes such as the quinone outside inhibitors or various contact or penetrant fungicides (N.A. Mitkowski, personal observation), particularly during summer months. This is especially true when managers are also regularly using PGRs such as trinexapac-ethyl, paclobutrazol, or flurprimidol for fear of compounded PGR effects on cool-season putting greens.

Research regarding plant growth regulator effects of DMI fungicides on turfgrass is generally consistent but there have been some conflicting studies when trials are undertaken in the field. Although a number of studies have demonstrated increased clipping weights on turf using propiconazole, studies have shown decreases in clipping weights using other DMI fungicides (Kane and Smiley, 1983; McCullough et al., 2006; Pennypacker et al., 1982; Reicher and Throssell, 1997; Xunzhong and Schmidt, 2000). Kane and Smiley (1983) reported that variable field responses have resulted with studies using triazole fungicides on Poa pratensis L. despite consistent results in growth chamber experiments. The researchers suggested that the complex nature of the field environment (variable temperatures, precipitation, drought stress, soil types, etc.) was likely to be responsible for these results. Pennypacker et al. (1982) found that temperature and precipitation have a significant impact on observed PGR-induced effects of DMI fungicides, supporting Kane and Smiley's (1983) assertion.

Despite the complex interactions inherent in field based trials, it is important to understand potential unwanted effects that any fungicide may have on high-maintenance turf grown in different regional climates. In the Northeast in particular, few negative effects from DMI fungicides have been observed on creeping bentgrass greens. In the last decade, a number of new DMI fungicides have been registered for turfgrass use, often being touted as "safer" than older DMI active ingredients (causing fewer plant growth regulator effects) (N.A. Mitkowski, personal observation). This study was conducted to compare the effects of different DMI fungicides on clipping weight and rooting depth of established creeping bentgrass (Agrostis stolonifera L.) greens.

\section{Materials and Methods}

Tests were conducted on a Bridgehampton silt loam located at the Skogley Memorial Turfgrass Research Facility at the University of Rhode Island in Kingston with a $\mathrm{pH}$ of 6.2 and an organic matter percentage of 3.2. The green was originally established in 1983 and has been regularly topdressed two to four times each year since 2001, resulting in a homogeneous mixture of native silt loam and sand $2 \mathrm{~cm}$ deep with native silt loam present below this level. Turf was maintained with a reel-mower (Greensmaster Flex Mower 18; The Toro Company, Bloomington, IL) at a $0.33-\mathrm{cm}$ mowing height, irrigated as needed, and fertilized with a total of $2.0 \mathrm{~kg}$ nitrogen $(\mathrm{N}) / 100 \mathrm{~m}^{2}$ applied in four separate $0.5 \mathrm{~kg} \mathrm{~N} / 100 \mathrm{~m}^{2} \mathrm{~N}$ applications throughout the course of the season using a $25 \mathrm{~N}-5 \mathrm{P}-15 \mathrm{~K}$ 
greens-grade fertilizer (Lebanon Seaboard Corporation, Lebanon, PA). Applications were made May, June, July, and August. Plots measured $1.5 \mathrm{~m} \times 1.5 \mathrm{~m}$ with $0.3-\mathrm{m}$ borders permanently marked with lines cut into the turf using an commercial edger. Plots were arranged in a randomized complete blocks with four replicates on an original mixture of $83 \%$ 'Penncross' and $17 \%$ 'Penneagle' creeping bentgrass. Less than 5\% Poa annua invasion was present in any of the trial plots. During the second year of the trial, five replicates were used on the same green but in an adjacent area. The trial area was originally seeded in 1983 and has never been overseeded. Treatments were applied using a $\mathrm{CO}_{2}$-pressurized handheld sprayer fitted with TeeJet 8004VS Visiflow flat fan nozzles at a height of $\approx 14$ inches and 10 -inch spacing delivering $13.0 \mathrm{~L} / 100 \mathrm{~m}^{2}$ at $40 \mathrm{psi}$, $\approx 30 \%$ more water than typically used on a green to negate any potential phytotoxic effects. Greens were mowed on a 6-d interval and clippings were removed.

During 2010, all treatments were first applied on 11 June and repeated every $14 \mathrm{~d}$ until 20 Aug., for a total of six applications. During 2011, all treatments were first applied on 20 June and repeated every $14 \mathrm{~d}$ until 15 Aug., for a total of five applications. For clipping weight sampling, each plot was double-cut using a Jacobsen e-Walk mower (Jacobsen, Charlotte, NC) that allowed for very precise clipping removal within the bounds of each marked plot. After each plot was mowed, the clippings from each replicate were transferred to a paper bag and allowed to dry for $3 \mathrm{~d}$ in an oven at $30^{\circ} \mathrm{C}$ and oven-dried weights were then recorded. In 2011, the area of each replicate was measured to the square inch to reduce potential error based on variation in plot size. In both 2010 and 2011, rooting depth was determined from five $2.54-\mathrm{cm}$ diameter core samples taken from each plot to a depth of $30 \mathrm{~cm}$. Soil was slowly removed from the bottom of each core until the first roots were detected and measurements were taken from the thatch/soil interface to the longest root section. In 2010, clippings were collected on 22 June, 29 June, 6 July, and 26 Aug. Root depths were measured on 22 June and 26 Aug. In 2011, clippings were collected on 1 July, 15 July, and 5 Aug. Root depths were measured on 18 Aug. Density and turfgrass quality ratings were observed visually.

In 2010, seven treatments were used (Table 1). Iprodione (Chipco 26GT) was used as a negative control with the assumption that it would not produce PGR effects. A treatment without any fungicide would have been badly damaged by dollar spot (Sclerotinia homeocarpa FT Bennett) that would have skewed the statistical analysis, a possible result demonstrated by Burpee et al. (1996). In 2011, an additional DMI fungicide was added to the trial as was a second negative control, chlorothalonil (Daconil Ultrex). To get an accurate comparison of the materials being tested, each of the DMI treatments was applied at an active ingredient equivalent (Table 1). That is, the rates that were used allowed for an equal amount of active ingredient to be used for each treatment. Although the maximum labeled rate of the paclobutrazol formulation used was $11.7 \mathrm{~mL} / 100 \mathrm{~m}^{2}$, equalizing the active ingredients required $35.0 \mathrm{~mL} /$ $100 \mathrm{~m}^{2}$, or a rate three times above maximum, leading to significant declines in turf quality.

Both clipping weights and root length data were analyzed using the GLM procedure and the Waller-Duncan mean comparison test used by SSPS Version 19.0 (IBM Corporation, Armonk, NY).

\section{Results}

During 2010, clipping weights were not statistically different among treatments at the first sampling but were statistically different on the three subsequent samplings (Table 2). In each of the following three samplings, clipping weights from paclobutrazol-treated turf (Tide Paclo) was significantly lower than any of the other materials. To maintain an equivalent amount of active ingredient among treatments, it was necessary to use three times the labeled use rate of paclobutrazol. Paclobutrazol is an very active PGR and consequently it should not be surprising that the paclobutrazol treatments would result in consistently lower clipping weights. The effect of paclobutrazol was not immediate and only became apparent after the second sampling. In addition to lower clipping weights, paclobutrazoltreated turf was extremely dark green or a bluish/gray and turfgrass density declined markedly as plots continued to be treated with paclobutrazol (Table 4).

On 29 June and 6 July 2010, highest clipping weights were obtained from the propiconazole-treated plots, although dates were statistically similar to all the other treatments except paclobutrazol and tebuconazole on 29 July 2010 and paclobutrazol on 6 July 2010. Quality and density differences among the treatments were minimal with the exception of paclobutrazol-treated turf. Although propiconazole has been reported to increase shoot growth in other studies and produce a darker color and reduced turf quality (Kane and Smiley, 1983; Reicher and Throssell, 1997; Xunzhong and Schmidt, 2000), it did not result in a statistically different improvement in turf quality during 2010 , although it did have the highest turf quality on both rating dates. It did produce a slightly noticeable darker color than all other treatments with the exception of paclobutrazole.

During 2011, no significant differences among clipping weights were observed until the last sampling on 5 Aug., when the clipping weights from the paclobutrazol-treated turf were significantly lower than all other treatments (Table 3). In 2011, it took longer for the growth regulator effects of paclobutrazol to be observed ( 7 weeks after the first application) but applications began later in the season. In addition, the summer of 2010 and the summer of 2011 were dramatically different at the trial site. The on-site weather station recorded twice as many $32+{ }^{\circ} \mathrm{C}$ days during July $2010(\mathrm{n}=7)$ vs. $2011(\mathrm{n}=3)$ and Summer 2010 was the hottest summer in New England since 1895 . This likely resulted in significant stress on the plants that may have translated into more easily observable PGR effects during 2010. Pennypacker et al. (1982) demonstrated that a reduction in clipping weight on Poa annua when treated with triadimefon was only observed when plants were grown under abnormally hot/wet conditions. Under other environmental regimes, no difference was observed. Although it did take longer for

Table 1. Trade name, active ingredient, labeled application rates, application rate used of fungicides, and plant growth regulator for field trials, 2010 and 2011.

\begin{tabular}{|c|c|c|c|c|c|}
\hline \multirow[b]{2}{*}{ Trade name ${ }^{\mathrm{z}}$ (active ingredient) } & \multirow[b]{2}{*}{ Trial years used } & \multicolumn{2}{|c|}{ Labeled rate $^{\mathrm{y}}\left(\mathrm{g}\right.$ or $\mathrm{mL}$ per $\left.100 \mathrm{~m}^{2}\right)$} & \multicolumn{2}{|c|}{ Application rate used in current study } \\
\hline & & Minimum & Maximum & $\overline{\left(\mathrm{g} \text { or } \mathrm{mL} \text { per } 100 \mathrm{~m}^{2}\right)}$ & $\overline{(\mathrm{kg} \text { a.i./ha) }}$ \\
\hline Chipco 26GT 2SC (iprodione) & $2010-11$ & 95.5 & 254.7 & 63.7 & 1.52 \\
\hline Tourney 50WG (metconazole) & $2010-11$ & 5.5 & 13.4 & 15.3 & 0.76 \\
\hline Banner MAXX 1.3MEC (propiconazole) & $2010-11$ & 16.0 & 127.3 & 51.0 & 0.80 \\
\hline Lynx 240SC (tebuconazole) & $2010-11$ & NA & NA & 31.8 & 0.81 \\
\hline Bayleton 50WG (triadimefon) & $2010-11$ & 7.6 & 61.0 & 15.3 & 0.76 \\
\hline
\end{tabular}

${ }^{2}$ Daconil Ultrex and Banner Maxx manufactured by Syngenta Professional Products, Greensboro, NC. Chipco 26GT, Lynx, and Bayleton manufactured by Bayer Environmental Science, Research Triangle Park, NC. Tourney manufactured by Valent Professional Products, Walnut Creek, CA. Eagle manufactured by Dow AgroSciences LLC, Indianapolis, IN. Trinity manufactured by BASF Corporation, Research Triangle Park, NC. Tide Paclo manufactured by Advan LLC, Roswell, GA.

${ }^{y}$ Lynx 240SC was never registered with the U.S. Environmental Protection Agency; therefore, no legal limits were established for its use - but during the time of its testing in the 1990s and early 2000s, typical university experimental protocols used rates between 31.8 and $63.7 \mathrm{~mL} / 100 \mathrm{~m}^{2}$.

$\mathrm{NA}=$ not applicable. 
Table 2. Total oven-dried clipping weight and creeping bentgrass rooting depth means, 2010.

\begin{tabular}{llllllll}
\hline & \multicolumn{3}{c}{ Total dried clipping wt $(\mathrm{g})^{\mathrm{z}}$} & & \multicolumn{2}{c}{ Rooting depth $(\mathrm{cm})$} \\
\cline { 2 - 4 } Treatment & $22 \mathrm{June}$ & $29 \mathrm{June}$ & $6 \mathrm{July}$ & $26 \mathrm{Aug}$. & & 22 June & 26 Aug. \\
\hline Iprodione & $23.1 \mathrm{NS}$ & $16.3 \mathrm{bc}$ & $22.43 \mathrm{~b}$ & $80.07 \mathrm{~b}$ & & $6.27 \mathrm{NS}$ & $7.41 \mathrm{NS}$ \\
Myclobutanil & 27.4 & $17.4 \mathrm{bc}$ & $24.37 \mathrm{~b}$ & $83.65 \mathrm{~b}$ & & 7.51 & 6.43 \\
Metconazole & 23.2 & $16.7 \mathrm{bc}$ & $20.07 \mathrm{ab}$ & $80.80 \mathrm{~b}$ & & 6.30 & 6.58 \\
Tebuconazole & 32.4 & $15.9 \mathrm{ab}$ & $21.67 \mathrm{~b}$ & $71.68 \mathrm{~b}$ & & 6.21 & 6.25 \\
Triadimefon & 30.3 & $18.8 \mathrm{bc}$ & $20.48 \mathrm{ab}$ & $85.77 \mathrm{~b}$ & & 6.73 & 7.75 \\
Propiconazole & 31.1 & $20.3 \mathrm{c}$ & $27.11 \mathrm{~b}$ & $75.18 \mathrm{~b}$ & & 7.23 & 6.48 \\
Paclobutrazol & 20.1 & $11.5 \mathrm{a}$ & $10.60 \mathrm{a}$ & $35.28 \mathrm{a}$ & & 7.09 & 6.38 \\
\hline
\end{tabular}

${ }^{\mathrm{z}}$ Means within a column followed by the same letter are not significantly different according to the WallerDuncan k-ratio $t$ test $(\mathrm{k}=100, P \leq 0.05)$.

$\mathrm{NS}=$ nonsignificant differences between any treatments within a column.

Table 3. Total oven-dried clipping weight and creeping bentgrass rooting depth means, 2011.

\begin{tabular}{|c|c|c|c|c|}
\hline \multirow[b]{2}{*}{ Treatment } & \multicolumn{3}{|c|}{ Total dried clipping wt $(\mathrm{g})^{\mathrm{z}}$} & \multirow{2}{*}{$\frac{\text { Rooting depth }(\mathrm{cm})}{18 \mathrm{Aug} .}$} \\
\hline & 1 July & 15 July & 5 Aug. & \\
\hline Chlorothalonil & $87.3 \mathrm{NS}$ & $22.9 \mathrm{NS}$ & $30.1 \mathrm{~b}$ & $6.56 \mathrm{NS}$ \\
\hline Iprodione & 83.0 & 18.3 & $31.4 \mathrm{~b}$ & 6.81 \\
\hline Myclobutanil & 76.5 & 21.6 & $29.4 \mathrm{~b}$ & 6.61 \\
\hline Metconazole & 81.5 & 20.9 & $29.2 \mathrm{~b}$ & 6.72 \\
\hline Tebuconazole & 86.0 & 19.5 & $32.1 \mathrm{~b}$ & 6.68 \\
\hline Triadimefon & 71.2 & 17.6 & $31.3 \mathrm{~b}$ & 6.90 \\
\hline Propiconazole & 72.4 & 18.5 & $29.3 \mathrm{~b}$ & 6.42 \\
\hline Triticonazole & 73.1 & 17.1 & $31.1 \mathrm{~b}$ & 6.30 \\
\hline Paclobutrazol & 81.0 & 15.7 & $6.8 \mathrm{a}$ & 6.73 \\
\hline
\end{tabular}

${ }^{\mathrm{z}}$ Means within a column followed by the same letter are not significantly different according to the WallerDuncan k-ratio $t$ test $(\mathrm{k}=100, P \leq 0.05)$.

NS = nonsignificant differences between any treatments within a column.

Table 4. Turfgrass quality ratings 21 and $42 \mathrm{~d}$ after treatment (DAT) in 2010 and 2011 trials.

\begin{tabular}{lcccc}
\hline & \multicolumn{2}{c}{$2010^{\mathrm{z}}$} & \multicolumn{2}{c}{2011} \\
\cline { 2 - 5 } & $21 \mathrm{DAT}^{\mathrm{y}}$ & $42 \mathrm{DAT}$ & $21 \mathrm{DAT}$ & $42 \mathrm{DAT}$ \\
\hline Chlorothalonil & $6.7 \mathrm{NS}$ & - & $7.0 \mathrm{NS}$ & $\mathrm{a}$ \\
Iprodione & 7.0 & $6.3 \mathrm{a}$ & 6.7 & $6.7 \mathrm{ab}$ \\
Myclobutanil & 7.3 & $6.7 \mathrm{a}$ & 7.0 & $6.3 \mathrm{~b}$ \\
Metconazole & 7.2 & $6.0 \mathrm{a}$ & 6.7 & $7.0 \mathrm{ab}$ \\
Tebuconazole & 7.0 & $6.7 \mathrm{a}$ & 7.8 & $7.3 \mathrm{ab}$ \\
Triadimefon & 7.5 & $7.8 \mathrm{a}$ & 7.0 & $7.3 \mathrm{ab}$ \\
Propiconazole & - & - & 7.3 & $7.7 \mathrm{a}$ \\
Triticonazole & 6.2 & $4.7 \mathrm{~b}^{\mathrm{x}}$ & 6.7 & $6.7 \mathrm{ab}$ \\
Paclobutrazol & & 5.8 & $3.5 \mathrm{c}$ \\
\hline
\end{tabular}

${ }^{\mathrm{z}}$ Quality ratings determined using modified National Turfgrass Evaluation Program guidelines where $9=$ outstanding turf (incorporating color, density, uniformity, disease, and damage), $1=$ dead, and 6 or above $=$ acceptable.

${ }^{y}$ Means within a column followed by the same letter are not significantly different according to the WallerDuncan k-ratio $t$ test $(\mathrm{k}=100, P \leq 0.05)$.

${ }^{\mathrm{x}}$ Growth regulation from paclobutrazol was more significant than other treatments because it was applied at almost three times the maximum labeled rate.

NS = nonsignificant differences between any treatments within a column.

the effects of paclobutrazol to be measured in 2011, the quality of the turf did begin to decline by the third week after the first application, accompanied by the onset of bluish/gray coloration, but the quality decline was not statistically different until the second rating at $42 \mathrm{~d}$ after treatment. Because 2011 was considered a milder summer, plants were under much less stress and this may have delayed the regulating effects of paclobutrazol until much later into the season. Similar to 2010, propiconazole produced slightly darker foliar color (compared with the markedly darker turf in the paclobutrazol treatment) and the only decline in turf quality was observed in paclobutrazol-treated turf (Table 4). Chlorothalonil and propiconazole did provide a slight increase in turf quality that was statistically significant, if not depth alone may not provide an entirely accurate picture of the PGR effects of DMI fungicides on roots.

\section{Discussion}

As previously mentioned, inconsistent and variable field responses often occur with field studies using triazole fungicides to assess PGR effects. The results of this study were relatively consistent with few differences observed among treatments and trial years. Although propiconazole did statistically increase clipping weight compared with other treatments on two rating dates in 2010, the increase was not substantial and was not observed in 2011. The most consistent result was that high levels of paclobutrazol statistically and substantially reduced clipping weights compared with other treatments when rates were equalized to those of labeled DMI fungicides. The results of this study indicate that there were no substantial differences on clipping yield reduction or root depth reduction among the DMI fungicides tested under field conditions when applied to creeping bentgrass. Although no differences on rooting depth were observed in either year, it should be noted that rooting depth is a single method for estimating root quantity and other methods such as root mass or total branching may have been influenced by the chemical treatments.

Although there is concern among turfgrass managers over the potential PGR effects of DMI fungicide applications during the summer, the results do not substantiate these concerns within the parameters tested in a cool, humid climate. In addition, few managers in the Northeast region would make biweekly applications of DMI fungicides for an entire summer, suggesting that the concern over the potential negative impacts may be overstated. This study does not address DMI fungicides applied to Poa annua greens or the potential for DMI phytotoxicity. However, in a 1-year field study, Kaminski (2009) examined combinations of trinexapac-ethyl, paclobutrazol, and triticonazole and found all individual and combined treatments resulted in higher quality turf than non-treated controls on Poa annua. Some DMI fungicides can cause phytotoxicity when used at high rates on creeping bentgrass, especially when used during summer months in high heat (N.A. Mitkowski, personal observation). McCullough et al. (2006) showed phytotoxicity to bermudagrass from fenarimol application in the greenhouse at high temperatures, including burning to leaves yellowing and reduction in clipping weights that may have been a result of foliar damage. However, the concern over phytotoxicity is separate from PGR effects and bermudagrass has repeatedly been observed to suffer from phytotoxicity in the field at rates that are safe on creeping bengtrass. In addition, the current study does not address the use of DMI fungicides in combination with other PGRs. Burpee et al. (1996) and Fidanza et al. (2006) demonstrated that PGR use may increase the efficacy of fungicides 
but did not address the effect of such a combination on actual growth rate through clipping yield. In the current study, high rates of PGRs (paclobutrazol) have correspondingly increased levels of plant growth suppression and a combination of DMI fungicides and a PGR are likely to be observed as additional growth retardation that may be undesirable. In addition, such combinations, particularly trinexapac-ethyl (Primo MAXX) and a DMI fungicide, may be more phytotoxic on $P o a$ annua greens in high heat than either product by itself. Additional factors such as extremely low height of cut (under 0.125 inch), high traffic, compaction, and low levels of fertilization may also increase potential negative effects of DMI fungicides on plant growth or quality.

\section{Literature Cited}

Bigelow, C.A., R.E. Schmidt, and D.R. Chalmers. 1995. Creeping bentgrass putting green turf as influenced by trinexapac-ethyl and propiconazole application. Amer. Soc. Agron. Annu. Mtg. Abstr. p. 150.

Buchenauer, H. and F. Grossman. 1977. Triadimefon: Mode of action in plants and fungi. Neth. J. Plant Pathol. 83:93-103.

Burpee, L.L., D.E. Green, and S.L. Stephens. 1996 Interactive effects of plant growth regulators and fungicides on epidemics of dollar spot in creeping bentgrass. Plant Dis. 80:1245-1250.

Fidanza, M.A., H.C. Wetzel, III, M.L. Agnew, and J.E. Kaminski. 2006. Evaluation of fungicide and plant growth regulator tank-mix programs on dollar spot severity of creeping bentgrass. Crop Prot. 25:1032-1038.

Fungicide Resistance Action Committee. 2012. FRAC code list: Fungicides sorted by mode of action (including FRAC Code numbering). Fungicide Resistance Action Committee. 14 June 2013. <http://www.frac.info/publication/anhang/ FRAC-Code-List2011-final.pdf $>$.

Kaminski, J.E. 2009. Phytotoxicity to Poa annua following repeated application of Trinity, Banner Maxx and experimental fungicides, p. 33-35. In Guillard, K. (ed.). 2008 Turfgrass research report of the University of Connecticut. UCONN, Storrs, CT.
Kamrin, M. 1997. Pesticide profiles: Toxicity, environmental impact and fate. Lewis Publishers, CRC Press, New York, NY.

Kane, R.T. and R.W. Smiley. 1983. Plant-growth regulating effects of systemic fungicides applied to Kentucky bluegrass. Agron. J. 75:469473.

McCullough, P.E., L.B. McCarty, and H. Liu. 2006. Response of 'TifEagle' bermudagrass (Cynodon dactylon $\times$ C. transvaalensis) to fenarimol and trinexapac-ethyl. Weed Technol. $20: 1-5$.

Pennypacker, B.W., P.L. Sanders, L.V. Gregory, E.P. Gilbride, and H. Cole, Jr. 1982. Influence of triadimefon on the foliar growth and flowering of annual bluegrass. Can. J. Plant Pathol. $4: 259-262$.

Reicher, Z.J. and C.S. Throssell. 1997. Effect of repeated fungicide applications on creeping bentgrass turf. Crop Sci. 37:910-915.

Xunzhong, Z. and R.E. Schmidt. 2000. Application of trinexapac-ethyl and propiconazole enhances superoxide dismutase and photochemical activity in creeping bentgrass (Agrostis stoloniferous var. palustris). J. Amer. Soc. Hort. Sci. 125:47-51. 